\title{
Fatores de risco ambientais e teratogênicos associados às malformações congênitas: um estado do conhecimento
}

\author{
Factores de riesgo ambiental y teratogénico asociados con \\ malformaciones congénitas: un estado de conocimiento
Environmental and teratogenic risk factors associated with congenital malformations: a state of knowledge

\author{
Julia da Fonseca Lopes ${ }^{1}$ \\ Manuella Gonçalves Vieira ${ }^{2}$ \\ Estela Souza Castro ${ }^{3}$
}

\begin{abstract}
Resumo
Este artigo é oriundo de um estudo que teve como objetivo conhecer o que tem sido investigado nas produções científicas com temáticas relacionadas às malformações congênitas. Para tanto, foi realizado um estado do conhecimento sobre os fatores de risco ambientais e teratogênicos associados a essas malformações. A coleta e produção dos dados foi realizada a partir de um levantamento de teses e dissertações, defendidas entre 2012 e 2018, com o descritor anomalias congênitas (DeCS) na Biblioteca Digital Brasileira de Teses e Dissertações (BDTD) do Instituto Brasileiro de Informação em Ciência e Tecnologia (IBICT). Dos 85 estudos encontrados, foram selecionados 9 , dos quais emergiram três categorias temáticas de análise.
\end{abstract}

Palavras-Chave: anomalias congênitas; estado do conhecimento; fatores de risco; teratogênese.

\section{Resumen}

Este artículo proviene de un estudio que tuvo como objetivo saber lo que se ha investigado en producciones científicas con temas relacionados con malformaciones congénitas. Por lo tanto, se realizó un estado de conocimiento sobre los factores de riesgo ambientales y teratogénicos asociados con estas malformaciones. La recopilación y producción de datos se realizó a partir de una encuesta de tesis y disertaciones, defendida entre 2012 y 2018, con el descriptor anomalías congénitas (DeCS) en la Biblioteca Digital Brasileña de Tesis y Disertaciones (BDTD) del Instituto Brasileño de Información en Ciencias. y Tecnología (IBICT). De los 85 estudios encontrados, se seleccionaron 9 de los cuales surgieron tres categorías temáticas de análisis.

Palabras claves: anomalías congénitas; estado de conocimiento; factores de riesgo; teratogénesis.

\begin{abstract}
This article comes from a study that aimed to know what has been investigated in scientific productions with themes related to congenital malformations. Therefore, a state of knowledge about the environmental and teratogenic risk factors associated with these malformations was performed. Data collection and production were performed from a survey of theses and dissertations, defended between 2012 and 2018, with the descriptor congenital abnormalities (DeCS) in the Brazilian Digital Library of Theses and Dissertations (BDTD) of the Brazilian Institute of Science Information. and Technology (IBICT). Of the 85 studies found, 9 were selected from which three thematic categories of analysis emerged.
\end{abstract}

\footnotetext{
${ }^{1}$ Mestranda em Educação; Universidade Federal do Rio Grande - FURG, Rio Grande, Rio Grande do Sul, Brasil;ju.flopes@hotmail.com

2 Graduada em Psicologia; Faculdades Anhanguera; Rio Grande, Rio Grande do Sul, Brasi; manuellagvieira@gmail.com

${ }^{3}$ Acadêmica do Curso de Pedagogia; Universidade Federal do Rio Grande-FURG, Rio Grande, Rio Grande do Sul, Brasil; estelasouzacastros@gmail.com
} 
Keywords: congenital abnormalities; state of knowledge; risk factors; teratogenesis.

\section{Introdução}

As anomalias congênitas, ou malformações congênitas, são caracterizadas por alterações morfológicas ou anatômicas que exibem manifestações clínicas diversas. Constituindo-se em um grupo de desordens de etiologia multifatorial, essas malformações podem ser causadas por disfunções genéticas únicas ou cromossômicas, por desnutrição de micronutrientes, ou ainda, por fatores teratogênicos e ambientais (SÃO PAULO, 2012; WHO, 2014). De acordo com o Global Report on Birth Defects, anualmente, no mundo, cerca de 7,9 milhões de bebês - $6 \%$ do total de nascimentos - nascem com alguma malformação congênita de ordem genética ou parcialmente genética, enquanto outras centenas de milhares nascem com malformações congênitas desenvolvidas após a concepção. Estas últimas ocorrem, especialmente, pela exposição materna a agentes teratogênicos, como medicamentos, álcool, tabaco, drogas ilícitas, rubéola, radiação, poluição ambiental, entre outros. Cerca de 5 a $10 \%$ são malformações não-genéticas e estão relacionadas à exposição destes agentes teratogênicos, além de forças mecânicas e ocorrência de acidentes vasculares que podem interferir no desenvolvimento fetal (CHRISTIANSON, HOWSON \& MODELL, 2006).

Este artigo parte de um estudo realizado por um grupo de pesquisa com foco em Inclusão, de uma universidade federal do Sul do Brasil. As pesquisas realizadas neste grupo abrangem estudos sobre o desenvolvimento infantil desde o período pré-natal. O estudo que deu origem à escrita deste artigo esteve centrado em realizar um levantamento de pesquisas brasileiras que investigam as malformações congênitas, com o objetivo principal de conhecer os tipos de ocorrências mais frequentes e os fatores de risco ambientais e/ou teratogênicos associados. Os estudos denominados como Estado do Conhecimento possuem caráter bibliográfico e visam mapear as produções científicas para identificar quais aspectos e dimensões vêm sendo destacadas e privilegiadas, bem como as condições pelas quais estas pesquisas têm sido produzidas. Busca-se, assim, identificar, registrar e categorizar estudos contemplados em periódicos, dissertações, teses e livros que permitam compreender e refletir sobre o estado alcançado pelo conhecimento em determinada área ou temática, sua dimensão, tendências e vertentes teórico-metodológicas (FERREIRA, 2002; MOROSINI, 2015; SOARES \& MACIEL, 2000). 
Para a coleta e produção dos dados, foi realizado um levantamento de pesquisas defendidas no período entre 2012 e 2018, na Biblioteca Digital Brasileira de Teses e Dissertações (BDTD) do Instituto Brasileiro de Informação em Ciência e Tecnologia (IBICT), a partir da busca pelo descritor anomalias congênitas (DeCS - Descritores em Ciências da Saúde). Os resultados apresentaram 85 pesquisas, dais quais 9 foram selecionadas, seis dissertações e três teses. A seleção foi realizada por meio da leitura dos resumos, através da qual foram priorizadas pesquisas contempladas pela temática dos fatores de risco ambientais e/ou teratogênicos associados às malformações congênitas.

\section{Resultados}

Emergiram do levantamento e da revisão das pesquisas, três categorias temáticas, a saber: 1) Prevalência e incidência de malformações congênitas, composta de três pesquisas (duas dissertações e uma tese); 2) Malformações congênitas específicas, com cinco pesquisas (três dissertações e duas teses) e 3) Percepção de risco teratogênico, contemplada por uma dissertação. Para fins de organização, os resultados serão apresentados em subseções individuais para cada categoria temática, nas quais as pesquisas serão descritas de acordo com a ordem apresentada nas tabelas em que constam os/as autores/as, títulos e objetivos.

\subsection{Prevalência e incidência de malformações congênitas}

As pesquisas compreendidas nesta categoria buscaram investigar questões relacionadas à prevalência e à incidência de malformações congênitas em diversas regiões brasileiras. Constatou-se três produções, conforme mostra a Tabela 1:

Tabela 1: Categoria temática "Prevalência e incidência de malformações congênitas".

\begin{tabular}{|c|c|c|}
\hline Autor/Ano & Título & Objetivos principais \\
\hline $\begin{array}{c}\text { CARDOSO, G. } \\
\text { C. }(2015) \\
\text { Dissertação }\end{array}$ & $\begin{array}{c}\text { Identificação de 'clusters' de doenças } \\
\text { genéticas em populações isoladas do } \\
\text { Brasil }\end{array}$ & $\begin{array}{c}\text { Estabelecer um censo de isolados populacionais com alta } \\
\text { prevalência de doenças genéticas ou anomalias congênitas de } \\
\text { causa ambiental ou desconhecida a fim de identificar } \\
\text { possíveis "clusters" geográficos de mucopolissacaridose tipo } \\
1 \text { no Brasil. }\end{array}$ \\
\hline $\begin{array}{c}\text { OLIVEIRA, C. } \\
\text { F. (2014) } \\
\text { Tese }\end{array}$ & $\begin{array}{c}\text { Incidência, fatores de risco e } \\
\text { consequências de defeitos congênitos } \\
\text { em recém-nascidos e natimortos }\end{array}$ & $\begin{array}{c}\text { Analisar os recém-nascidos e natimortos com defeitos } \\
\text { congênitos nascidos no município de São José do Rio } \\
\text { Preto/SP, durante um ano, para identificar os tipos de } \\
\text { defeitos, etiologias, fatores de risco e consequências. }\end{array}$ \\
\hline $\begin{array}{c}\text { COCHAK, M. } \\
\text { R. (2017) } \\
\text { Dissertação }\end{array}$ & $\begin{array}{c}\text { Associação de cromossomopatias } \\
\text { humanas com uso e ocupação do solo } \\
\text { em regiões brasileiras }\end{array}$ & $\begin{array}{c}\text { Analisar as cromossomopatias humanas em regiões } \\
\text { brasileiras no período de dez anos e relacioná-las ao uso e } \\
\text { ocupação de solo. }\end{array}$ \\
\hline
\end{tabular}

Fonte: Dados da pesquisa. 
RELACult - Revista Latino-Americana de Estudos em Cultura e Sociedade

\subsubsection{Identificação de 'clusters’ de doenças genéticas em populações isoladas do Brasil}

A pesquisa de Gabriela Costa Cardoso (2015) buscou determinar um censo de isolados populacionais no Brasil que apresentam alta prevalência de malformações congênitas de origem ambiental ou desconhecida, além de realizar um levantamento de dados, por meio de registros médicos da Rede MPS Brasil", no intuito de identificar possíveis "clusters" geográficos de mucopolissacaridose do tipo I (MPS I). Por cluster entende-se "uma área e/ou período de tempo em que o risco superficial para uma determinada doença está elevado, isto é, o número de casos está em excesso para dados esperados (Wakefield et al., 2000)" (CARDOSO, 2015, p. 20).

De acordo com Cardoso (2015, p. 20), "muitas populações geograficamente isoladas são caracterizadas por apresentar prevalência maior do que a esperada [...] para uma determinada doença, em uma população que vive em uma área geográfica definida ao longo de um período de tempo". Em vista disso, a pesquisadora destaca que além de se identificar os indivíduos com algum diagnóstico de malformação congênita, torna-se importante também identificar as populações com índices elevados de doenças genéticas. Para tanto, utilizou a metodologia do Centro Nacional de Isolados (CENISO) ${ }^{5}$, caracterizada por uma revisão da literatura e pelo método RUMOR, definido como "qualquer tipo de relato, oral ou escrito, sobre a ocorrência não usual de uma anomalia congênita ou uma exposição como fator de risco" (CASTILLA \& SCHÜLER-FACCINI, 2014 apud CARDOSO, 2015, p. 30).

Os resultados da pesquisa de Cardoso (2015) apontam que, dentre os 236 rumores registrados no CENISO, 216 foram avaliados e, destes, 144 clusters de doenças genéticas foram confirmados, sendo que mais da metade $(57,4 \%)$ dos rumores registrados estavam localizados na região Nordeste, atribuindo o maior índice de consanguinidade nessa região como uma possível interpretação destes dados. A pesquisadora verificou, ainda, a partir do levantamento de dados da Rede MPS Brasil, 151 casos de MPS I, dos quais 14,7\% apresentaram consanguinidade parental. A prevalência dos casos foi percebida na região Sudeste e, segundo a pesquisadora, os dados analisados sugerem três possíveis clusters de MPS I, localizados na fronteira entre Minas Gerais e São Paulo, no norte do Rio Grande do

\footnotetext{
${ }^{4}$ A Rede MPS Brasil fica localizada no Serviço de Genética Médica do Hospital de Clínicas, em Porto Alegre. Ver mais em: http://www.ufrgs.br/redempsbrasil/.

${ }^{5}$ Censo Nacional de Isolados (CENISO) de populações brasileiras com alta frequência de malformações congênitas ou expostas a fatores de risco genéticos ou ambientais. Desenvolvido desde 2009 pelo Instituto Nacional de Ciência e Tecnologia (INaGeMP) do $\mathrm{CNPq}$, grupo de pesquisa dedicado à Genética Médica Populacional. Ver mais em: http://www.inagemp.bio.br/ceniso/.
} 
Sul e no leste de Santa Catarina.

Cardoso (2015) concluiu que a partir da identificação de comunidades que apresentam doenças genéticas em frequências alteradas, torna-se possível adequar a assistência médica de acordo com as especificidades da população, bem como atuar em intervenções de acompanhamento e aconselhamento genético às famílias de pessoas diagnosticadas em clusters confirmados.

\subsubsection{Incidência, fatores de risco e consequências de defeitos congênitos em recém- nascidos e natimortos}

Camila Oliveira (2014) defende que entre as múltiplas consequências das malformações congênitas, a mortalidade infantil é uma das mais importantes, uma vez que "é indicadora da saúde de uma comunidade ou país por estar diretamente associada a fatores como saúde materna, qualidade e acesso a serviços de saúde, condições socioeconômicas e práticas de saúde pública" (OLIVEIRA, 2014, p.19). Para o planejamento de estratégias preventivas e terapêuticas, tornam-se imprescindíveis a identificação e o conhecimento sobre a incidência, os fatores de risco e as consequências dessas malformações.

Com o objetivo de avaliar a incidência de malformações congênitas, bem como suas possíveis causas e consequências, em sua pesquisa de doutorado, Oliveira (2014) analisou, de forma prospectiva, todas as crianças nascidas entre o período de março de 2011 a fevereiro de 2012, no município de São José do Rio Preto, em São Paulo. No tocante aos aspectos metodológicos, a pesquisa foi realizada por meio de avaliações genético-clínicas, do levantamento de informações da Declaração de Nascido Vivo (DNV) de 158 indivíduos que apresentaram malformações congênitas, bem como a investigação de consequências dessas malformações em relação aos períodos de internação, aos custos hospitalares e à frequência de mortalidade em menores de um ano de idade. Para a avaliação de características demográficas, foi realizada uma análise estatística descritiva.

No que diz respeito à incidência, o estudo correspondeu a 3,2\%, dado que, dos 5.204 nascimentos durante o período da pesquisa, 169 apresentaram malformações congênitas, dos quais 158 eram recém-nascidos vivos e 11 natimortos. Essa incidência corrobora com os índices obtidos em estudos de diferentes populações do mundo, os quais estimam ser de 3 a 5\% (GILL et al., 2012 apud OLIVEIRA, 2014). 
Segundo Herbert et al. (2012), citados por Oliveira (2014), há uma incidência maior de malformações congênitas entre as crianças que apresentam baixo peso ao nascer ( $\leq$ 2.500g), o que corrobora com os achados da pesquisa de Oliveira. Os dados mostram uma diferença significativa no que diz respeito ao período gestacional e ao peso: o período gestacional das mães de crianças com malformações congênitas variou entre 20 e 42 semanas e $42 \%$ apresentaram baixo peso ao nascer, enquanto nos grupos controle a variação foi de 33 a 41 semanais e 14,7\% apresentaram baixo peso ao nascer. Contudo, a pesquisadora salienta que deve ser levado em consideração

que o diagnóstico pré-natal de anomalias graves pode ter um impacto sobre os resultados neonatais, pois em fetos com diagnóstico pré-natal de DCs maiores, geralmente, a opção por parto cesárea é frequente e realizado mais precocemente. Este tipo de procedimento pode explicar o peso inferior (CALISTI et al., 2012; O'NEILL, et al., 2013) (OLIVEIRA, 2014, p. 52).

A pesquisadora salienta o fato de que diversas mulheres têm adiado a maternidade. A idade materna avançada, considerada acima de 35 anos, indica riscos para o desenvolvimento de malformações congênitas. Tal fato foi observado em seu estudo como um dos fatores de risco, dado que a idade acima de 35 anos foi mais frequente entre as mães de crianças com malformações congênitas. No que diz respeito aos fatores de risco ambientais, conferiu-se que o diabetes gestacional, recorrência familiar, abortos espontâneos anteriores e ingestão de álcool foram mais frequentes nos casos com malformações congênitas.

As malformações mais frequentes no grupo investigado, foram as cardiopatias congênitas isoladas, seguidas da síndrome de Down, de malformações do tubo neural e do trato urinário e a polidactilia. Dentre os casos de etiologia cromossômica, alterações cariotípicas foram detectadas em $14,8 \%$ das crianças com malformação congênita, sendo a maioria do tipo numérica, das quais $46 \%$ das mães apresentavam idade igual ou superior a 35 anos. Os dados indicaram, ainda, que nos casos com cromossomopatias, as mais frequentes (64\%) eram a trissomia do cromossomo 21.

No que diz respeito às consequências das malformações congênitas em relação aos períodos de internação, aos custos hospitalares e à frequência de mortalidade, foi observado que a internação de crianças com malformações congênitas foi sete vezes mais longa do que a de crianças sem malformações congênitas. A respeito dos custos hospitalares em casos de malformação congênita, Oliveira (2014, p. 57) destaca que os principais preditores são "o tempo de internação, tempo de permanência em UTI, tempo na sala de operação, quantidade de cirurgias, complicações pós-operatórias, permanência em incubadora e infecções hospitalares". Os dados que obteve no período de sua pesquisa indicaram que o custo total foi 
seis vezes mais alto nos casos de malformação congênita. É nesse sentido que a pesquisa salienta a importância de se investir em estratégias informativas e preventivas.

No tocante à frequência de mortalidade em menores de um ano de idade, os óbitos foram mais frequentes entre o grupo de crianças com malformações congênitas, compreendendo $21 \%$ desses indivíduos. De acordo com a pesquisadora, dados fornecidos pela Secretaria da Saúde do município estudado indicaram um total de 36 óbitos de crianças menores de um ano de vida durante o período da pesquisa, das quais $33(91,7 \%)$ faziam parte do grupo com malformações congênitas estudado. Nas Declarações de Nascido Vivo avaliadas, os 158 casos foram notificados, contudo, em 64 (40,5\%) deles, o preenchimento foi considerado incorreto (opção "não"), ainda que as malformações pudessem ser detectadas ao nascimento.

Em vista desses resultados, Oliveira (2014) conclui enfatizando a importância da identificação e do conhecimento sobre a incidência, os fatores de risco e as consequências das malformações congênitas para a elaboração de políticas públicas em saúde, estratégias preventivas e terapêuticas como uma possibilidade para reduzir tanto os riscos da população, como os custos com tratamento. Além disso, salienta também a necessidade de mais pesquisas nessa área, inclusive em outros municípios brasileiros.

\subsubsection{Associação de cromossomopatias humanas com uso e ocupação do solo em regiões brasileiras}

A pesquisa de Marcos Roberto Cochak (2017) analisou as cromossomopatias humanas oriundas de regiões brasileiras no período entre 2005 e 2015, e as correlacionou ao uso e ocupação do solo. Segundo o pesquisador, as cromosomopatias, ou alterações cromossômicas, representam uma das principais causas de abortamentos espontâneos, problemas relacionados à infertilidade e grande número de malformações congênitas. Estão presentes em cerca de $1 \%$ dos recém-nascidos vivos e em $2 \%$ dos diagnósticos pré-natais em mulheres com idade acima de 35 anos. Cerca de $50 \%$ dos abortos espontâneos no primeiro trimestre apresentam alterações cromossômicas. De etiologia multifatorial, as cromossomopatias podem ocorrer devido a fatores hereditários, idade materna avançada, exposição a substâncias teratogênicas e ambientais, como os resíduos industriais e agrotóxicos (ASTBURY, 2011; NUSSBAUM, MCINNES \& WILLARD, 2007; UEKER et al., 2016 apud COCHAK, 2017, p. 17).

Essas alterações são classificadas em numéricas ou estruturais, e envolvem os cromossomos autossômicos, sexuais ou ambos. Dentre as alterações numéricas, as 
aneuploidias, que envolvem ganhos ou perdas de cromossomos, são as mais frequentes, presentes em 5\% das gestações conhecidas (TURNPENNY \& ELLARD, 2007 apud COCHAK, 2017). O diagnóstico das cromossomopatias é realizado mediante a análise do cariótipo, e a sua identificação é basilar para o tratamento e prognóstico, bem como para o levantamento de dados sobre a incidência, herdabilidade e riscos de recorrência.

Em vista disso, Cochak (2017) realizou um estudo documental retrospectivo de resultados de amostras de pacientes com indicação de exames diagnósticos para alterações cromossômicas, no banco de dados de amostras enviadas de diversas regiões brasileiras para o estudo citogenético no Laboratório Álvaro (DASA), o qual é referência nacional. O pesquisador verificou que, dos 43.672 resultados de exames de cariótipo, 17\% apresentaram alterações cromossômicas, sendo que $77 \%$ foram as aneuploidias, seguidas das estruturais (16\%) e numéricas e estruturais concomitantes (7\%). Do total de alterações, 79,2\% envolvia cromossomos autossômicos, $20,3 \%$ cromossomos sexuais e $0,48 \%$ envolvia ambos.

Quanto à caracterização das cromossomopatias por regiões brasileiras, Cochak (2017) verificou que a região Sul apresentou a maior proporção de alterações cromossômicas por habitante (6/100.00), seguida das regiões Centro-Oeste e Norte (4/100.000), Nordeste (3/100.000) e Sudeste (2/100.000). Quanto ao uso e ocupação do solo, verificou que as áreas urbanizadas de todas as regiões brasileiras apresentaram uma maior probabilidade de ocorrência de cromossomopatias (50 a 90\%), seguidas por áreas de lavouras permanentes (40 a 50\%). Além de apresentar maiores proporções, a região Sul também apresentou maior probabilidade de ocorrência de alterações cromossômicas, dado que esta região é caracterizada por apresentar $85 \%$ da população urbanizada, com amplas áreas de pastagens e lavouras, sendo que

o Estado do Paraná tem $53 \%$ do seu território ocupado por lavouras permanentes, com consumo médio aproximado de agrotóxicos de $5,5 \mathrm{Kg} / \mathrm{ha}$, abaixo da média regional (IBGE, 2015). Nestas regiões, é fato o alto consumo de agrotóxicos. O uso de agrotóxicos de modo excessivo ou sem técnicas para aplicação oferece riscos ao surgimento de doenças congênitas, devido ao potencial genotóxico dos seus ingredientes, de forma a alterar o funcionamento de órgãos, células e danificar proteínas e ácidos nucléicos, DNA ou RNA (COSTA \& TEIXEIRA, 2012) (COCHAK, 2017, p. 52)

Os dados de sua pesquisa demonstram que existe uma probabilidade maior de ocorrência de alterações cromossômicas em regiões com alto índice de uso de agrotóxicos, com risco ampliado em áreas urbanizadas. De acordo com o pesquisador, estudos como esse são escassos no Brasil, especialmente os que investigam as prevalências das 
cromossomopatias associadas às distribuições geográficas. Esses estudos são importantes, visto que os indicadores sobre os riscos de incidência e recorrência de cromossomopatias podem auxiliar no aconselhamento genético, além de viabilizarem o levantamento de informações e de hipóteses estratégicas para a elaboração de políticas públicas.

\subsection{Malformações congênitas específicas}

Nesta categoria temática estão inseridos cinco estudos que tiveram como foco as malformações congênitas previamente determinadas pelos/as pesquisadores/as, em especial a microcefalia e as fissuras orofaciais, conforme mostra a Tabela 2:

Tabela 2: Categoria temática "Malformações congênitas específicas".

\begin{tabular}{|c|c|c|}
\hline Autor/Ano & Título & Objetivos principais \\
\hline $\begin{array}{l}\text { OLIVEIRA, W. } \\
\text { K. (2017) } \\
\text { Tese }\end{array}$ & $\begin{array}{l}\text { Emergência de Saúde Pública de } \\
\text { Importância Internacional: resposta } \\
\text { brasileira à síndrome congênita } \\
\text { associada à infecção pelo Zika vírus, } \\
2015 \text { e } 2016\end{array}$ & $\begin{array}{c}\text { Descrever os principais marcos da epidemia de Zika vírus } \\
\text { (ZIKAV) no Brasil, relacionando às ações de saúde pública } \\
\text { adotadas e caracterizar as diferenças regionais com base nas } \\
\text { taxas de incidência de ZIKAV em gestantes e de prevalência } \\
\text { de microcefalia em casos registrados no SINAN e no } \\
\text { formulário RESP. }\end{array}$ \\
\hline $\begin{array}{l}\text { HERBER, S. } \\
\text { (2017) } \\
\text { Tese }\end{array}$ & $\begin{array}{l}\text { Avaliação de crianças notificadas ao } \\
\text { nascimento por microcefalia e/ou } \\
\text { alterações do sistema nervoso central } \\
\text { no estado do Rio Grande do Sul } \\
\text { (2015-2016) }\end{array}$ & $\begin{array}{c}\text { Avaliar e descrever as causas de microcefalia dos RN } \\
\text { notificados por microcefalia e/ou alterações do SNC no Rio } \\
\text { Grande do Sul. }\end{array}$ \\
\hline $\begin{array}{l}\text { MARANHÃO, } \\
\text { S. C. (2014) } \\
\text { Dissertação }\end{array}$ & $\begin{array}{l}\text { Análise clínico-epidemiológica das } \\
\text { fissuras lábio-palatinas no Estado da } \\
\text { Bahia }\end{array}$ & $\begin{array}{l}\text { Realizar uma revisão sistemática dos aspectos etiológicos } \\
\text { relacionados ao desenvolvimento das fissuras lábio-palatinas. }\end{array}$ \\
\hline $\begin{array}{l}\text { MOURA, } \\
\text { J. R. (2014) } \\
\text { Dissertação }\end{array}$ & $\begin{array}{l}\text { Perfil clínico-epidemiológico dos } \\
\text { portadores de fissuras orofaciais em } \\
\text { residentes do Estado da Bahia: um } \\
\text { estudo descritivo }\end{array}$ & $\begin{array}{l}\text { Descrever o perfil clínico-epidemiológico dos portadores de } \\
\text { fissuras orofaciais congênitas, residentes no estado da Bahia, } \\
\text { atendidos no Centro de Reabilitação de Anomalias } \\
\text { Craniofaciais do Hospital Santo Antônio, no período de } 2008 \\
\text { a } 2013 \text {. }\end{array}$ \\
\hline $\begin{array}{l}\text { MARTINS, } \\
\text { C.M. R. (2014) } \\
\text { Dissertação }\end{array}$ & $\begin{array}{c}\text { Estudo da influência do uso de } \\
\text { agrotóxicos e de polimorfismo do } \\
\text { gene GSTT1 na etiologia de fissuras } \\
\text { labiopalatais em pacientes do Estado } \\
\text { do Pará }\end{array}$ & $\begin{array}{l}\text { Investigar a associação entre o polimorfismo (rs4630) no } \\
\text { gene GSTT1 e a exposição a agrotóxicos na etiologia das } \\
\text { FLPS. }\end{array}$ \\
\hline
\end{tabular}

Fonte: Dados da pesquisa.

\subsubsection{Emergência de Saúde Pública de Importância Internacional: resposta brasileira à síndrome congênita associada à infecção pelo Zika vírus, 2015 e 2016}

A tese de Wanderson Kleber de Oliveira (2017) teve como objetivo descrever os principais marcos da epidemia de Zika Vírus (ZIKAV) no Brasil, relacionando-os às ações de saúde pública adotadas pelo governo brasileiro no período de janeiro de 2015 a novembro de 
2016. Além disso, sua pesquisa buscou caracterizar as diferenças regionais com base nas taxas de incidência de ZIKAV em gestantes e de prevalência de microcefalia no Brasil. Para tanto, realizou uma revisão de literatura e uma análise descritiva e comparativa dos casos registrados em 2015 e 2016 nas bases de dados do Sistema de Informação de Agravos de Notificação (SINAN) e do formulário de Registro de Eventos de Saúde Pública (RESP).

De acordo com o pesquisador, a introdução do ZIKAV no Brasil ocorreu em três fases. A primeira fase, compreendida entre o período de janeiro a junho de 2015 , foi caracterizada pelos surtos de ZIKAV, tendo os primeiros casos identificados em Barra do Corda e Caxias, ambas no interior do Maranhão (MS, 2006 apud OLIVEIRA, 2017). Na segunda fase, compreendida entre julho e dezembro de 2015, o Ministério da Saúde declarou Emergência de Saúde Pública de Importância Nacional (ESPIN), em 11 de novembro, por meio da Portaria ${ }^{\circ}$ 1.813/2015, visando instituir o Centro de Operações de Emergências em Saúde Pública (COES) e propondo a adoção de medidas extraordinárias para resposta à emergência, conforme previsto na norma (MARTINES et al., 2016; MS, 2014 apud OLIVEIRA, 2017).

As ESPIN são compreendidas, no Brasil, como aquelas situações em que há a demanda urgente do emprego de medidas preventivas, de controle e contenção de riscos, danos e agravos à saúde pública, especialmente em virtude da ocorrência de situações epidemiológicas, desastres e/ou desassistência à população. Em situações epidemiológicas, incluem-se os surtos ou epidemias que apresentem risco de disseminação nacional (BRASIL, 2011 apud OLIVEIRA, 2017). A partir dos resultados das investigações de campo nesta segunda fase, alguns critérios foram identificados nos casos do ZIKAV como potencial ESPIN, destacados por Oliveira (2017, p. 57) como:

\begin{abstract}
A) Impacto Grave sobre a Saúde Pública: pela presença do vetor em todo o território nacional, o representava um risco significativo tanto para a saúde pública nacional quanto internacional, apesar de poucos óbitos terem sido identificados. Além disso, a ocorrência de surtos de ZIKAV no Brasil estava concentrada em população vulnerável sem exposição anterior ao vírus e em regiões de alta densidade populacional; B) Evento incomum ou inesperado: não se esperava óbito ou infecção congênita pelo ZIKAV e C) Risco significativo de propagação internacional: Por ser agente transmitido por vetores que estão presentes em todos os países da região, pela identificação do vírus em Pedro Juan Caballero na fronteira do Brasil com o Paraguai, além de casos suspeitos na Cidade do Leste e Concepción desse país.
\end{abstract}

$\mathrm{Na}$ terceira fase, compreendida entre janeiro e junho de 2016, a Organização Mundial da Saúde declarou Emergência de Saúde Pública de Importância Internacional (ESPII), em 1 de fevereiro de 2016 (WHO, 2016 apud OLIVEIRA, 2017).

Quanto às características clínicas da infecção pelo ZIKAV, esta pode gerar um 
espectro variável, desde uma manifestação sem apresentar sinais e/ou sintomas aparentes, com manifestações leves e autolimitadas, bem como uma manifestação com complicações neurológicas e por doença congênita. Essas manifestações clínicas são percebidas em cerca de $20 \%$ dos casos infectados. Apesar de não apresentar sintomatologia aparente, quando infectada, uma mulher em período gestacional poderá transmitir o vírus para o feto, o que pode ocasionar aborto espontâneo, óbito fetal ou malformações congênitas (FALUYI et al., 2000; MO, ALFEREZ SALADA \& TAMBYAH, 2016; MUSSO \& GUBLER, 2016; SHUAIB et al., 2016 apud OLIVEIRA, 2017).

As anormalidades relatadas sugerem que uma síndrome congênita, semelhante à rubéola congênita ou infecção por citomegalovírus, pode estar associada à infecção pelo ZIKAV durante a gestação, sugerindo - com base em estudos observacionais, de coorte e de caso-controle - que o ZIKAV é uma causa de microcefalia congênita e outras complicações neurológicas que, em conjunto, constituem a Síndrome Congênita do Zika Vírus (SCZ) (ARAÚJO et al., 2016; CALVET et al., 2016; MARTINES et al., 2016; MIRANDA-FILHO et al., 2016; PAHO, 2016; RUSSEL et al., 2016; VAN DER LINDEN et al., 2016 apud OLIVEIRA, 2017).

Oliveira (2017) constatou que, entre 2015 e 2016, 41.473 casos de gestantes com quadro clínico compatível ao ZIKAV foram notificados e, no mesmo período, 1.950 casos de microcefalia foram notificados, dentre os quais $70 \%$ foram confirmados por método de imagem. Quanto às diferenças regionais, observou que no ano de 2015, o Nordeste compreendeu a região mais afetada e, em 2016, apesar de não ter apresentado o mesmo padrão do ano anterior, foi observada uma possível segunda onda de casos de microcefalia a partir do segundo semestre, em especial, na região Centro-Oeste. Esse padrão corrobora com o nexo causal entre infecção pelo ZIKAV na gestação e a manifestação da SCZ.

Apesar do ZIKAV ser um agente etiológico pouco conhecido, Oliveira (2017, p. 108) concluiu que ele "pode desencadear um espectro clínico que varia de infecções inaparente, casos graves com teratogênese e até mesmo evoluir para o óbito”. Ainda que o Ministério da Saúde brasileiro tivesse poucas evidências que sustentasse a causalidade entre a infecção pelo ZIKAV e a manifestação da SCZ, o pesquisador considerou oportunas as ações de governo, em especial, por terem resultado na mobilização a nível nacional e internacional, o que impulsionou a pesquisa e desenvolvimento em todas as áreas do conhecimento relacionadas.

\subsubsection{Avaliação de crianças notificadas ao nascimento por microcefalia e/ou alterações} do sistema nervoso central no estado do Rio Grande do Sul (2015-2016) 
No mesmo segmento do estudo descrito anteriormente, Silvani Herber (2017) pontua que a notificação compulsória de recém-nascidos com microcefalia - instituída pelo Ministério da Saúde em consequência do aumento no número de casos após o surto de Zika Vírus (ZIKAV) em 2015 - proporcionou mais subsídios para estudos sobre os fatores etiológicos e a prevalência dessa malformação congênita. Considerando que a distribuição geográfica do ZIKAV ocorreu de modo diferenciado no Brasil, e que houve menor número de infecções no Sul do país, a pesquisadora pontua o Rio Grande do Sul como uma região importante para a avaliação etiológica de microcefalia nesse Estado.

Em vista disso, a pesquisa de Silvani Herber (2017) teve como objetivo avaliar e descrever as causas de microcefalia de recém-nascidos notificados por microcefalia e/ou alterações do Sistema Nervoso Central (SNC) no Rio Grande do Sul durante o surto de ZIKAV. Para tanto, realizou um estudo transversal, no qual avaliou 162 recém-nascidos notificados entre o período de 2015 a 2016. Do total, 99 casos foram avaliados de forma retrospectiva, com base em revisão de banco de dados, e 63 de forma prospectiva, em ambulatório específico do Hospital de Clínicas de Poro Alegre. A avaliação clínica foi realizada conforme as orientações do protocolo do Ministério da Saúde, que priorizavam a investigação de doenças infecciosas, a avaliação genética e o exame de imagem cerebral.

Entre os principais resultados, Herber (2017) destaca que dentre os 162 recémnascidos avaliados, 58,6\% apresentavam microcefalia grave. Referente à etiologia, 73 dos casos tiveram causa definida, sendo 19,3\% provenientes de infecções congênitas, seguidas de malformação isolada do SNC (12,4\%) e síndromes genéticas (11,7\%). Dos 31 casos de microcefalia provenientes de infecções congênitas, a sífilis congênita foi a mais frequente no estudo, compreendendo 14 (45,2\%) casos, seguida de toxoplasmose $(25,8 \%)$, citomegalovírus (19.3\%) e ZIKAV (9.7\%). A maior parte dos casos de infecção congênita apresentou lesões neurológicas graves - principalmente os casos de ZIKAV e citomegalovírus -, o que pode ocasionar atraso no desenvolvimento neurológico e sequelas nestas crianças ao longo da primeira infância.

A pesquisadora identificou alterações preocupantes, que aumentam o risco de morbimortalidade em recém-nascidos, como a microcefalia grave, presente em metade dos casos notificados, alterações neurológicas detectadas por exames de imagem, baixo peso ao nascer e a prevalência de recém-nascidos pequenos para a idade gestacional. Herber (2017) alerta, ainda, para o crescente aumento de sífilis no mundo, ao identificá-la como a causa mais presente em seu estudo, devido, possivelmente, à maior probabilidade de transmissão da mãe para o feto. Em conclusão, independente da presença de ZIKV, a pesquisadora considera 
importante avaliar as demais infecções congênitas e as causas desconhecidas associadas à microcefalia no Rio Grande do Sul.

\subsubsection{Análise clínico-epidemiológica das fissuras lábio-palatinas no Estado da Bahia}

A dissertação de Samário Cintra Maranhão (2014) é composta por dois manuscritos. No primeiro, o pesquisador apresenta uma revisão sistemática sobre os aspectos epidemiológicos associados às fissuras labiopalatinas não sindrômicas em diferentes populações. No segundo, discorre sobre a sua pesquisa, a qual buscou identificar o perfil epidemiológico de indivíduos com fissuras na Bahia. A revisão sistemática foi realizada por meio de um levantamento de artigos, compreendendo o período de 2012 e 2013, nas bases Bireme e Lilacs, com os descritores fenda labial, etiologia das fissuras e anormalidades congênitas.

Caracterizadas como malformações congênitas comuns em humanos, as fissuras labiopalatinas podem surgir como "característica de uma síndrome ou como consequência de alterações cromossômicas causadas por fatores ambientais como a exposição materna a determinados agentes teratogênicos durante a gestação" (MARANHÃO, 2014, p. 16). A prevalência das fissuras não sindrômicas pode variar de acordo com a origem geográfica, etnia, gênero e padrão socioeconômico, contudo, estima-se que, na população mundial, a prevalência seja de 1 a cada 500 a 2000 nascidos vivos. Em 1946, Fogh-Andersen observou a existência de um elemento hereditário associado às fissuras não sindrômicas, no entanto, fatores ambientais também podem estar associados (GORLIN, COHEN \& HENNEKAM, 2001; JAMILIAN, NAYERI \& BABAYAN, 2007; MOSSEY et al., 2002; MURTHY \& BHASKAR, 2009; NATSUME et al., 2000; VIEIRA, 2008 apud MARANHÃO, 2014).

Considerando a multiplicidade de fatores que pode influenciar no desenvolvimento de fissuras orofaciais, Maranhão (2014) evidencia a necessidade de se realizar levantamentos epidemiológicos sobre o perfil dos indivíduos acometidos e os aspectos ambientais envolvidos nessas ocorrências. Em vista disso, sua pesquisa compreendeu um estudo transversal de base hospitalar, entre o período de 2011 a 2014, com 692 usuários dos três centros de referência para fissurados orofaciais da Bahia. Foram realizadas entrevistas com os usuários e/ou responsáveis legais e exames para a classificação do tipo de fissura. Por meio da estatística descritiva, o pesquisador avaliou a ocorrência dos tipos de fissura, os fatores ambientais associados e as áreas em que os tipos de fissuras foram mais frequentes.

Os resultados do estudo de Maranhão (2014) mostraram que, compreendendo 53,8\% 
da amostra, as fissuras labiopalatinas (unilaterais $35,4 \%$ e bilaterais $18,4 \%$ ) tiveram maior prevalência, seguidas das fissuras labiais $(23,3 \%)$ e das fissuras palatinas $(22,8 \%)$. O lado esquerdo foi significativamente mais acometido, compreendendo $45,1 \%$ do total da amostra, o que corrobora com maior parte da literatura mundial (GARDENAL et al., 2011; CERQUEIRA et al., 2005; FRANÇA, \& LOCKS, 2003; MENG et al., 2006; GRAZIOSI, BOTTINO \& CASTILHO SALGADO, 1998 apud MARANHÃO, 2014). De acordo com Freitas (2004), citado por Maranhão (2014), ainda não há uma explicação definitiva sobre a predominância de fissuras no lado esquerdo, mas considera-se que, "no início da gestação, haja um maior aporte de sangue no lado direito do concepto devido à maior pressão sanguínea na artéria carótida interna direita" (FREITAS, 2004 apud MARANHÃO, 2014, p. 53).

No que diz respeito à distribuição das fissuras no Estado da Bahia, nas macrorregiões a prevalência foi maior na região metropolitana de Salvador $(44,4 \%)$, seguida do centro-sul $(17,4 \%)$ e centro-norte $(13,7 \%)$. Já nas microrregiões, a diferença foi estatisticamente significativa quanto aos tipos de fissura. Dentre as cinco microrregiões que registraram maior frequência, em quatro delas a fissura labiopalatina unilateral prevaleceu, salvo Vitória da Conquista, em que a fissura labial isolada unilateral (37,5\%) foi o tipo mais prevalente.

Concernente às características sociodemográficas da amostra estudada, não houve diferença significativa entre os sexos (49,6\% masculino e 50,4\% feminino). Contudo, quando observados separadamente cada tipo de fissura, constatou-se que a fissura labiopalatina foi mais prevalente entre o sexo masculino, correspondendo a 63,7\% da amostra, enquanto que o mesmo tipo de fissura compreende $44,2 \%$ do sexo feminino. Referente à cor da pele, a prevalência de fissuras foi maior entre as pessoas que se autodeclararam negras $(35,4 \%)$, pardas $(33,9 \%)$ e brancas $(24,9 \%)$. Quando associados ao tipo de fissura, a fissura labiopalatina unilateral foi mais prevalente nos grupos autodeclarados brancos $(32,7 \%)$, pardos $(38,8 \%)$, negros $(32,6 \%)$ e amarelos (46,4\%); no grupo autodeclarado índio, a fissura palatina isolada (40\%) foi a mais prevalente, seguida da fissura labiopalatina unilateral (30\%). Cabe destacar que Maranhão (2014) reconhece a dificuldade em relacionar a etnia por meio da autopercepção do indivíduo, haja vista a miscigenação da população brasileira, "pois a autopercepção de cor pode variar na concepção de cada indivíduo como também ser influenciada pelo perfil cultural de uma dada população" (Ibid, p. 54).

O estudo apontou, ainda, que maior parte dos entrevistados era proveniente de zona urbana, com baixo índice de escolaridade, sendo que 52,7\% dos entrevistados não haviam concluído o ensino fundamental. Contudo, deve-se atentar às características sociodemográficas da amostra, uma vez que a idade média foi de 13 anos. De acordo com 
Lynch e Kaplan (2003) citados por Maranhão (2014, p. 55),

O nível educacional é considerado um indicador confiável para definir o status socioeconômico e é refletido na habilidade pessoal em interpretar informações relacionadas à saúde. A renda se relaciona diretamente com as condições materiais que influenciam a saúde, como condições de moradia, cuidados médicos e estilo de vida.

Outro dado importante é que maior parte dos entrevistados era proveniente de famílias de baixa renda, sendo 56,3\% das famílias cuja renda mensal era de até um salário mínimo. Além disso, 62,3\% dos genitores eram beneficiários de algum programa de assistência social para famílias de baixa renda. No entanto, Maranhão (2014) salienta que os dados de seu estudo podem não corresponder exatamente à realidade da população geral do Estado da Bahia, pois "procede a possibilidade de que as famílias de mais alta renda podem não ter procurado atendimento e/ou tratamento nos centros pesquisados, os quais pertencem ao serviço público de saúde” (Ibid., p. 55).

Entre os outros fatores avaliados, constatou-se que a idade materna, o uso de álcool, fumo, drogas ou suplementação vitamínica durante a gestação, histórico familiar e cor da pele não exerceram influência estatisticamente significativa para as fissuras labiopalatinas da população estudada. Maranhão (2014) conclui que são necessárias novas investigações para determinar o risco associado entre os fatores ambientais e a ocorrência de fissuras labiopalatinas, tendo em vista que o conhecimento destes fatores e da etiologia das fissuras pode auxiliar no desenvolvimento de estratégias preventivas e ações de assistência efetiva no atendimento a estes indivíduos.

\subsubsection{Perfil clínico-epidemiológico dos portadores de fissuras orofaciais em residentes do} Estado da Bahia: um estudo descritivo

A pesquisa de Jamille Rios Moura (2014) enfatiza a escassez de estudos brasileiros referentes aos fatores de risco e à prevalência de fissuras orofaciais, em especial, devido às irregularidades na notificação dos casos referentes às malformações congênitas nas DNVs. Para a pesquisadora, informações como essas são importantes para o reconhecimento do problema, bem como para o planejamento de políticas de assistência e prevenção. Com o objetivo de descrever o perfil epidemiológico de pessoas com fissuras orofaciais, residentes do Estado da Bahia, Moura (2014) realizou um estudo epidemiológico observacional do tipo descritivo. Analisou 319 prontuários de indivíduos com fissuras orofaciais não sindrômicas, 
atendidos entre o período de 2008 a 2013 no Centro de Reabilitação de Anomalias Craniofaciais do Hospital Santo Antônio, na cidade de Salvador, Bahia. Os dados coletados dos prontuários foram submetidos à análise descritiva de informações sobre o perfil sociodemográfico do/a paciente e da mãe, o uso de medicamentos na gestação, os aspectos clínicos e cirúrgicos relacionados às fissuras, o histórico familiar da malformação e a consanguinidade dos pais.

Os resultados do estudo de Moura (2014) indicam que não houve diferença estatisticamente significativa na prevalência de fissuras orofaciais entre os sexos, dado que dentre os 319 prontuários analisados, 51,1\% dos casos compreendiam indivíduos do sexo feminino. Referente ao cadastramento no Centro durante o período estudado, observou que $90,5 \%$ dos indivíduos não tiveram tratamento cirúrgico prévio, e foi predominante o cadastro de indivíduos na faixa etária menor de um ano de idade (46,2\%). A história familiar de fissura foi observada em $29,8 \%$ dos casos estudados e 7,1\% dos casos reportaram algum grau de consanguinidade entre os pais.

A análise dos tipos de fissuras orofaciais teve como base a classificação recomendada Spina (1972). Dentre os 319 prontuários analisados, a fissura transforame incisivo foi a mais diagnosticada $(34,4 \%)$, seguida da pós-forame incisivo $(33,7 \%)$. Quanto à extensão das fissuras, as mais frequentes correspondiam à fissura transforame incisivo unilateral $(26,6 \%)$. A distribuição dos tipos de fissura de acordo com os sexos, apresentou uma prevalência de fissuras do tipo pós-forame incisivo em pessoas do sexo feminino $(40,1 \%)$ e transforame incisivo nas do sexo masculino $(38,4 \%)$.

No que diz respeito aos dados sociodemográficos, a renda familiar predominante foi inferior a um salário mínimo, compreendendo 38,9\% dos casos. Um nível socioeconômico baixo é um fator de risco que pode estar associado a um déficit nutricional e a maior tensão emocional no período gestacional, os quais podem causar malformações congênitas (DRESSLER \& SANTOS, 2000; HANSEN et al., 2001 apud MOURA, 2014). Referente às condições de moradia, $75,8 \%$ dos indivíduos possuíam casa própria com água encanada $(79,4 \%)$, rede de esgoto $(54,5 \%)$ e energia elétrica $(95,6 \%)$, contudo, em alguns casos, as famílias não usufruíam destes serviços básicos. Tais condições ambientais potencializam riscos teratogênicos específicos e o risco para o desenvolvimento das fissuras orofaciais (MESSER et al., 2010 apud MOURA, 2014).

Quanto às características sociodemográficas e ao estilo de vida materno, observou-se que 48,6\% das mães apresentavam, durante a gestação, idade materna entre 16 e 25 anos, considerada, segundo o Ministério da Saúde, fora da faixa etária de risco. Dentre os 168 casos 
válidos para o estudo, 59,5\% das mães fez uso de medicamentos no período gestacional, sendo que os mais utilizados compreenderam vitaminas $(79,4 \%)$, antibióticos $(9,1 \%)$, anticoncepcionais $(2,5 \%)$ e anti-hipertensivos (2,5\%). À época do cadastramento, $48,9 \%$ das mães haviam concluído o ensino fundamental, o que também pode estar associado à ocorrência dessa malformação, dado que estudos têm sugerido que "indivíduos com baixo nível educacional, quando comparadas aqueles com nível superior, tendem a fumar mais, a consumir alimentos menos saudáveis e a usar menos frequentemente suplementação vitamínica durante o período gestacional” (MOURA, 2014, p. 50-51).

A maior parte dos indivíduos $(54,4 \%)$ era oriunda de zona urbana e residia na região metropolitana de Salvador. De acordo com Hall et al. (2005) citados por Moura (2014), quando comparadas às áreas rurais, as diferenças na prevalência de malformações congênitas em áreas urbanas podem indicar possíveis fatores de risco relacionados ao ambiente físico e social, bem como ao acesso aos serviços de saúde, que geralmente localizam-se em grandes centros urbanos. Em conclusão, a pesquisadora refere que os principais achados do seu estudo indicam uma variedade de fatores ambientais aos quais as mães podem ser expostas durante a gestação e que podem contribuir para o desenvolvimento de fissuras orofaciais. Contudo, destaca que as limitações próprias do modelo de estudo observacional descritivo dificultam o estabelecimento de associações ou inferências causais entre as variáveis estudadas para a compreensão de suas influências na etiologia dessas malformações.

\subsubsection{Estudo da influência do uso de agrotóxicos e de polimorfismo do gene GSTT1 na etiologia de fissuras labiopalatais em pacientes do Estado do Pará}

A pesquisa de Cláudia Maria da Rocha Martins (2014) salienta que há um alto índice de fissuras orofaciais no Estado do Pará, especialmente em pessoas oriundas de zonas rurais, no nordeste do Estado, região essa que faz uso indiscriminado de agrotóxicos com alto potencial teratogênico. Em vista disso, sua pesquisa teve como objetivo investigar a associação entre o polimorfismo (rs4630) no gene GSTT1 e a exposição a agrotóxicos na etiologia das fissuras labiopalatinas, além de analisar o padrão das alterações de fala dos indivíduos diagnosticados de acordo com o tipo da fissura.

Para tanto, foram realizadas análises fonoaudiológica e molecular com 83 pacientes do Hospital Ophir Loyola, com fissuras labiais, palatinas ou labiopalatinas, oriundos do Estado do Pará e residentes da zona rural e capital, além de arguições e aplicação de questionários com as mães, para identificar as características socioambientais, como hábitos tabagistas e 
etilistas, e o nível de exposição a agrotóxicos ou outros compostos teratogênicos. Dentre os 83 pacientes, verificou-se que a idade média era de 7 anos e que $64 \%$ eram do sexo masculino. A frequência dos tipos de fissura apresentou prevalência em $69 \%$ para as fissuras labiopalatinas, seguidas das fissuras palatinas (19\%) e das fissuras labiais (12\%). 25\% das mães que participaram do estudo, relataram ter contato cotidiano com agrotóxicos, incluindo-se o período gestacional do/a filho/a com fissura.

Em relação à análise fonoaudiológica, alterações de fonemas foram verificadas em pacientes com fissuras orofaciais. A pesquisadora observou que independente de fatores como idade do/a paciente, tipo de fissura e sua classificação, as alterações de fala e dos fonemas constituem um padrão frequente nesses casos. As alterações verificadas no estudo compreenderam os distúrbios articulatórios simples e compensatórios, e as alterações relacionadas a fatores dento-oclusais e à inadequação velofaríngea.

Quanto ao estudo molecular, este consistiu em seis análises estatísticas diferentes, a partir das quais verificou-se que a presença do alelo $\mathrm{C}$ no genótipo dos indivíduos pode influenciar no metabolismo de xenobióticos e aumentar o risco para o desenvolvimento de fissuras. Também foi observado que o genótipo T/T foi menos presente na amostra estudada quando comparada à população geral, sugerindo que esse genótipo possa proporcionar maior eficiência em metabolizar pesticidas, evitando, assim, esse tipo de malformação.

\subsection{Percepção de risco teratogênico}

Constatou-se apenas um estudo que visa determinar o modo como mulheres em idade fértil (gestantes e não gestantes) percebem os riscos teratogênicos provenientes de procedimentos terapêuticos e do uso de medicamentos durante o período gestacional, cujas informações constam na Tabela 3:

Tabela 3: Categoria temática "Percepção de risco teratogênico"

\begin{tabular}{|c|c|c|}
\hline Autor/Ano & Título & Objetivos principais \\
\hline $\begin{array}{c}\text { PONS, E. S. } \\
\text { (2012) } \\
\text { Dissertação }\end{array}$ & $\begin{array}{c}\text { Percepções de risco teratogênico por } \\
\text { gestantes e mulheres em idade fértil no } \\
\text { Sul do Brasil: uma abordagem } \\
\text { qualitativa e quantitativa }\end{array}$ & $\begin{array}{c}\text { Caracterizar a percepção de risco teratogênico por gestantes e } \\
\text { mulheres em idade fértil. }\end{array}$ \\
\hline
\end{tabular}

Fonte: Dados da pesquisa

\subsubsection{Percepções de risco teratogênico por gestantes e mulheres em idade fértil no Sul do} Brasil: uma abordagem qualitativa e quantitativa 
A dissertação de Emília da Silva Pons (2012) pontua que 1\% das malformações congênitas de etiologia conhecida são causadas pelo uso de medicamentos. Ainda que a prevalência seja baixa, mostram-se evidentes as preocupações sobre os riscos de seus usos durante o período gestacional. A pesquisadora salienta que podem ser perigosas as orientações sobre se evitar completamente o uso de medicamentos no período inicial da gestação, dado que cerca de $8 \%$ das gestantes precisam de tratamento medicamentoso contínuo em virtude de doenças crônicas. Contudo, o uso de medicamentos durante a gestação demanda algumas precauções na escolha do fármaco e da dosagem apropriada, em especial, devido às alterações fisiológicas decorrentes da gravidez e aos riscos teratogênicos para o feto (CZEIZEL, 1999; BANHIDY et al., 2005; LOEBSTEIN \& KOREN, 2002 apud PONS, 2012).

Para a pesquisadora, uma percepção equivocada do risco teratogênico pode influenciar na adesão ou não a um tratamento medicamentoso seguro durante a gestação, visto que a percepção de risco é altamente individualizada, incluindo-se a isto fatores culturais, religiosos, sociais, bem como a forma como o indivíduo percebe a sua própria saúde (CONOVER \& POLIFKA, 2011 apud PONS, 2012, p. 23). Pons (2012) reconhece a escassez de estudos que tenham por objetivo avaliar o risco de malformações fetais cuja causa esteja associada à relutância ou não adesão ao tratamento medicamentoso materno. Em vista disso, investigou as concepções e a percepção de gestantes e de mulheres em período fértil sobre o risco teratogênico da exposição à radioterapia, bem como a medicamentos comumente utilizados por gestantes, como o paracetamol, a metoclopramida e misoprostol. Para tanto, durante o período entre fevereiro e agosto de 2011, realizou entrevistas e grupos focais com 287 mulheres em período fértil (144 gestantes e 143 não gestantes), entre 15 e 49 anos de idade, usuárias de três centros públicos de saúde de Porto Alegre.

Entre os principais achados de sua pesquisa, Pons (2012) constatou que $81,1 \%$ das gestantes fez uso de algum tipo de medicamento na gestação. Contudo, independente do período gestacional, as gestantes manifestaram rejeição ao uso de medicamentos, sendo o butilbrometo de escopolamina (Buscopan) e os antieméticos os mais evitados. Essa rejeição foi relacionada à oposição entre natural e artificial, e o risco atribuído aos medicamentos:

como algo artificial, todo o medicamento é percebido apresentando em si mesmo um perigo ao organismo. É neste sentido que há uma preferência, por parte das mulheres que participaram dos grupos focais, aos produtos e práticas tidas como naturais -- como chás, vitaminas e repouso -- em contraposição à rejeição dos medicamentos (PONS, 2012, p. 42). 
A questão do perigo foi associada, pelas participantes, à sua potência, isto é, avaliam o risco teratogênico mediante a classificação dos medicamentos em fortes e fracos. Essa lógica dicotômica pressupõe que, para essas mulheres, não possuem riscos as exposições e os medicamentos que por elas são percebidos como fracos, ao passo que aqueles percebidos como fortes e/ou perigosos, produzem efeitos negativos no organismo e devem ser evitados, em especial, durante a gestação. Dentre os medicamentos classificados como fortes, foram considerados "os antibióticos, anti-inflamatórios, antiespasmódicos e remédios para os nervos, além de injeções" (PONS, 2012, p. 42). Na classificação de medicamentos fracos, encontra-se o paracetamol, que segundo a pesquisadora, está associado ao seu acesso e uso generalizado para todas as faixas etárias. Segundo Pons (2012, p. 44),

\begin{abstract}
A avaliação do risco se dá, em geral, a partir de experiências próximas ou ocorridas com familiares. Há a informação genérica sobre um potencial risco, mas que, por não ser exata e não ter uma fonte identificável (dizem que), não permite que o risco seja mensurado com precisão. Desta forma, o potencial risco é generalizado para o produto ou exposição e não para a dosagem.
\end{abstract}

Tal fato pode estar relacionado à inexistência de consenso, por parte dos profissionais, sobre os riscos dos medicamentos durante a gestação, dado que as limitações éticas no tocante às pesquisas clínicas dificultam a avaliação de segurança do uso de medicamentos em humanos. De acordo com a pesquisadora, essa ausência de consenso entre os profissionais da saúde e da indústria farmacêutica é nítida, em especial quando recomendam a privação do uso de medicamentos durante a gestação, o que pode influenciar na percepção de risco, bem como na não adesão a tratamentos seguros. Desse modo, seu estudo salientou que "a classificação científica do risco é diferente da lógica utilizada pelo público leigo para avaliar o fenômeno" (PONS, 2012, p. 48), pois de modo contrário à lógica científica, que verifica a potencialidade de risco para malformações congênitas com base em cálculos probabilísticos, as mulheres que participaram da pesquisa avaliam os riscos por meio de situações concretas:

Frente à dificuldade de operar a lógica probabilística, o cálculo sobre o risco se dá a partir das experiências de familiares e pessoas próximas. As malformações congênitas fazem parte da experiência das mulheres e, portanto, já é esperado que elas venham a ocorrer "naturalmente" - a maior parte delas já viu ou teve contato direto ou indireto com crianças com malformações. Essa presença esperada de crianças que nascem com malformação aparece nos dados do estudo a partir da avaliação do risco geral de malformações em uma posição intermediária ao risco dos medicamentos fracos e dos medicamentos fortes (PONS, 2012, p. 48-49). 
A partir da classificação de risco associada à potência dos medicamentos, muitas das entrevistadas relataram não fazer uso de alguns dos medicamentos prescritos por médicos. No entanto, fica evidente o reconhecimento correto, tanto de alguns medicamentos que beneficiam a saúde materna e do feto, como dos que prejudicam. Em conclusão, Pons (2012) verifica que a partir dessa lógica de classificação, os medicamentos paracetamol e metoclopramida não foram percebidos como teratogênicos, enquanto aqueles procedimentos e medicamentos considerados fortes, devem ser evitados na gravidez, como a exposição à radioterapia, o misoprostol e outras substâncias consideradas abortivas. Em vista disso, a autora sugere que as intervenções informativas sobre o uso de medicamentos no período gestacional, devem considerar essa lógica própria de classificação dos medicamentos e seus riscos. Assim, torna-se importante constar, em materiais impressos de orientação, a inclusão de dados numéricos mais acessíveis sobre as estimativas de risco teratogênico de medicamentos na gestação.

\section{Considerações finais}

Com o objetivo de realizar um levantamento de pesquisas brasileiras para conhecer as temáticas que vêm sendo destacadas em estudos sobre os fatores de risco ambientais e teratogênicos associados às malformações congênitas, verificou-se que as pesquisas epidemiológicas foram as mais frequentes em dissertações e teses defendidas no período de 2012 a 2018.

Os estudos compreendidos na categoria temática Prevalência e incidência de malformações congênitas evidenciaram a importância da realização de pesquisas que visam identificar os tipos de malformações congênitas mais frequentes, os fatores de risco associados, bem como as consequências que delas provêm. Os/as autores/as pontuam que tal conhecimento possibilita a elaboração de políticas públicas em saúde e o desenvolvimento de estratégias preventivas e terapêuticas, além de promover melhor adequação na assistência médica de acordo com as especificidades de cada população.

As pesquisas contempladas na categoria Malformações congênitas específicas, investigaram as características etiológicas de doenças genéticas, principalmente as fissuras orofaciais e as infecções pelo Zika Vírus, em especial a microcefalia. Alguns desses estudos realizaram levantamentos sobre a distribuição geográfica nas diversas regiões brasileiras, o que tem se mostrado potente para o campo científico, uma vez que esses dados mobilizam o desenvolvimento de pesquisas, como demonstrou Oliveira (2017) ao resgatar o histórico do 
surto de ZIKAV e relacioná-lo às ações do governo brasileiro diante deste cenário epidêmico. Apesar desta categoria ter contemplado pesquisas com foco no estudo de malformações específicas, os dados evidenciam a prevalência de outras mais, principalmente em regiões onde é elevado o uso de agrotóxicos, com risco ampliado, especialmente, em regiões urbanizadas e industriais.

Nesse sentido, promoções na área da saúde se tornam necessárias, principalmente no que diz respeito a esclarecimentos e orientações sobre os riscos teratogênicos de substâncias químicas presentes tanto no meio ambiente quanto em medicamentos e drogas lícitas e ilícitas, pois como pontua o estudo da categoria temática Percepção de risco teratogênico, as pessoas tendem a avaliar os produtos a partir de uma lógica própria de classificação, o que pode gerar resistência e, até mesmo, privação a tratamentos medicamentosos seguros, em especial durante o período gestacional. Pode-se dizer que isso ocorre, principalmente devido ao desconhecimento e à desinformação, potencializados pela falta de consenso entre os profissionais da saúde e da indústria farmacêutica, sobre os riscos de determinados medicamentos, como relataram as participantes do estudo de Pons (2012).

Considerando o exposto, reforçamos, em concordância com os/as autores/as dos estudos levantados, a relevância do tema, especialmente para que seja possível pensar, em nível de políticas públicas, formas de reduzir os riscos ambientais à população. Estudos como os contemplados neste artigo evidenciam a importância de projetos que visem elaborar estratégias informativas e de conscientização, com dados precisos e acessíveis à população leiga, principalmente para orientar gestantes e mulheres em período fértil sobre as prevalências das malformações congênitas e os fatores de risco associados, considerando as especificidades de cada região.

\section{Referências}

CARDOSO, G. C. Identificação de "clusters" de doenças genéticas em populações isoladas do Brasil. 2015. 78f. Dissertação (Mestrado em Genética e Biologia Molecular) Universidade Federal do Rio Grande do Sul, Porto Alegre, 2015. Disponível em: http://hdl.handle.net/10183/131933.

CHRISTIANSON, A.; HOWSON, C.; MODELL, B. Global Report on Birth Defects: the hidden toll of dying and disabled children. New York: White Plains, 2006.

COCHAK, M. R. Associação de cromossomopatias humanas com uso e ocupação do solo em regiões brasileiras: estudo retrospectivo de 2005 a 2015. 2017. 70 f. Dissertação (Mestrado em Biociências e Saúde) - Universidade Estadual do Oeste do Paraná, Cascavel, 2017. Disponível em: http://tede.unioeste.br/handle/tede/3568. 
FERREIRA, N. S. de A. As pesquisas denominadas "Estado da Arte". Educação \& Sociedade, ano XXIII, n. 79, p. 257-272, ago. 2002. ISSN 0101-7330. Disponível em: http://www.scielo.br/pdf/es/v23n79/10857.pdf. Acesso em: 14 ago. 2019.

HERBER, S. Avaliação de crianças notificadas ao nascimento por microcefalia elou alterações do sistema nervoso central no estado do Rio Grande do Sul (2015-2016). 2017. 108f. Tese (Doutorado em Medicina: Ciências Médicas) - Universidade Federal do Rio Grande do Sul, Porto Alegre, 2017. Disponível em: https://www.lume.ufrgs.br/handle/10183/164888.

MARANHÃO, S. C. Análise clínico-epidemiológica das fissuras lábio-palatinas no estado da Bahia. 2014. 73f. Dissertação (Mestrado em Odontologia) - Escola Bahiana de Medicina e Saúde Pública, Salvador, 2014. Disponível em: http://bdtd.ibict.br/vufind/Record/EBM_f48a2a5e29d38a82bb977b187763b535.

MOROSINI, M. C. Estado de conhecimento e questões do campo científico. Educação, v. 40, n. 1, p. 101-116, jan./abr. 2015. ISSN: 1984-6444. Disponível em: https://periodicos.ufsm.br/reveducacao/article/view/15822. Acesso em: 14 ago. 2019.

MARTINS, C. M. da R. Estudo da influência do uso de agrotóxicos e de polimorfismo do gene GSTT1 na etiologia de fissuras labiopalatais em pacientes do Estado do Pará. 2014. 64f. Dissertação (Mestrado em Neurociências e Biologia Celular) -- Universidade Federal do Pará, Belém, 2014. Disponível em: http://repositorio.ufpa.br/jspui/handle/2011/5948.

MOURA, J. R. Perfil clínico-epidemiológico dos portadores de fissuras orofaciais em residentes do Estado da Bahia: um estudo descritivo. 2014. 90f. Dissertação (Mestrado em Saúde Coletiva) - Universidade Estadual de Feira de Santana, Feira de Santana, 2014. Disponível em: http://tede2.uefs.br:8080/handle/tede/404.

OLIVEIRA, C. I. F. Incidência, fatores de risco e consequências de defeitos congênitos em recém-nascidos e natimortos. 2014. 138f. Tese (Doutorado em Genética) - Universidade Estadual Paulista Júlio de Mesquita Filho, São José do Rio Preto, 2014. Disponível em: https://repositorio.unesp.br/handle/11449/122185.

OLIVEIRA, W. K. de. Emergência de Saúde Pública de importância internacional: resposta brasileira à síndrome congênita associada à infecção pelo Zika vírus, 2015 e 2016. 2017. 108f. Tese (Doutorado em Epidemiologia) - Universidade Federal do Rio Grande do Sul, Porto Alegre, 2017. Disponível em: https://www.lume.ufrgs.br/handle/10183/163731.

PONS, E da S. Percepções de risco teratogênico por gestantes e mulheres em idade fértil no Sul do Brasil: uma abordagem qualitativa e quantitativa. 2012. 84f. Dissertação (Mestrado em Epidemiologia) - Universidade Federal do Rio Grande do Sul, Porto Alegre, 2012.

Disponível em: https://lume.ufrgs.br/handle/10183/117130.

SÃO PAULO. Declaração de Nascido Vivo. $2^{\mathrm{a}}$ ed. São Paulo: Secretaria Municipal da Saúde. Coordenação de Epidemiologia e Informação - CEInfo, 2012. 97p.

SOARES, M.; MACIEL, F. Alfabetização. Brasília: MEC/Inep/Comped, 2000. 
WHO. Birth defects surveillance: a manual for programme managers. Geneva: World Health Organization/CDC/ICBDSR, 2014. 115p. 